\title{
Prevalence, Incidence, and Epidemic Trends of Osteoarthritis Among Adults in Beijing, China, From 2008 to 2017
}

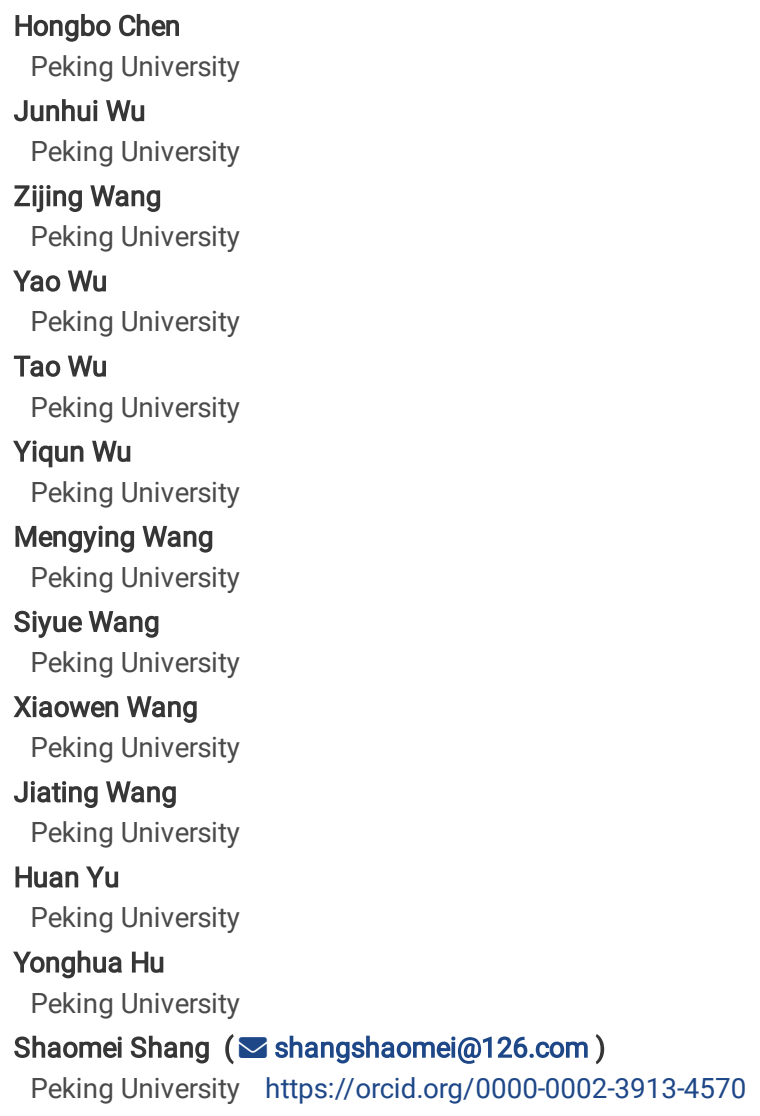




\section{Abstract \\ Objective}

To estimate the prevalence, incidence, and epidemic trend of diagnosed osteoarthritis from 2008 to 2017 in Beijing, China.

\section{Methods}

This was a retrospective serial cross-sectional study. We used health-insurance claims of 17.7 million adults for 2008-2017 to identify people over 18 yearsold with osteoarthritis. The population data for Beijing from China's 6th national census were applied to standardize the results. Trends in prevalence and incidence were analyzed using joinpoint regression.

\section{Results}

We identified 2,793,467 people with osteoarthritis between 2008 and 2017,60\% of which were women. The 10-year average age-standardized prevalence and incidence of osteoarthritis in Beijing was, respectively, $5.2 \%$ and 28.5 per 1000 person-years. Prevalence increased with age, surging after 55 years-old. The average crude prevalence for this decade was $14.9 \%$ for people over 55 years-old: $10.7 \%$ for males and $20.4 \%$ for females. The prevalence showed an increasing trend from 2008 to 2017 , including a period of rapid rise, with an annual percentage change of $44.3 \%$ from 2008 to 2011 (Pख0.05); the increase in prevalence was greatest in people under 35 years-old, with the an average annual percentage change of $36.1 \%(P<0.05)$.

\section{Conclusion}

We observed that the average age-standardized prevalence of diagnosed osteoarthritis in Beijing per decade was at a low-to-medium level compared to worldwide levels. Annual prevalence increased significantly from 2008 to 2017, with osteoarthritis being diagnosed at younger ages. More public health efforts are needed to prevent osteoarthritis in China.

\section{Introduction}

Osteoarthritis is a common chronic degenerative joint disease, which mainly manifests as pain, stiffness, and functional limitation of the affected joints, and can lead to disability [1]. The joints most vulnerable to osteoarthritis include the knees, hips, elbows, ankles, the lumbar spine, cervical spine, and hand joints. Osteoarthritis affects 240 million people worldwide [2], and it is estimated that $9.6 \%$ of men and $18.0 \%$ of women over 60 years-old have symptomatic osteoarthritis, worldwide [3]. The years lived with disability (YLDs) caused by osteoarthritis ranked tenth in China in 2016 [4], and the growth rate of YLDs due to osteoarthritis ranked fifth in Nordic countries [5]. Therefore, the disease burden caused by osteoarthritis is huge.

Many western countries have conducted epidemiological studies of osteoarthritis, including large-scale cross-sectional studies and longitudinal cohort studies [6-8]. However, in China, which is the largest developing country in the world, most epidemiological studies of osteoarthritis have had limited resources and used relatively small sample sizes $[9,10]$. Thus, they could not adequately assess the prevalence and incidence of osteoarthritis or its epidemic trends in recent years.

Beijing, the capital of China, is a metropolis of more than 20 million people, while aging, sedentary lifestyle, obesity, and other risk factors for osteoarthritis have been rapidly increasing $[11,12]$. What is the prevalence and incidence of osteoarthritis in the this city in recent years? Is it increasing year by year? We do not currently know the answer to these questions. Beijing has long-term detailed medical data, giving us the opportunity to observe a panoramic view of the large-scale epidemiological changes of osteoarthritis.

The aim of the present study was to estimate the prevalence, incidence and epidemic trends of diagnosed osteoarthritis from 2008 to 2017 in Beijing, using the Beijing Medical Claim Data for Employees (BMCDE). It is hoped that the results of this study will provide information about the future epidemic of osteoarthritis in other cities in China.

\section{Patients And Methods Data sources}

Data were obtained from the BMCDE, which records medical claims for all beneficiaries who have participated in urban employee basic medical insurance programs in Beijing. Due to the low proportion of the rural population and high employment rate, urban employee medical insurance is the main type of medical insurance in Beijing. At the end of 2017, nearly 18 million beneficiaries were included in the BMCDE, covering nearly $80 \%$ of the resident population of this city. Information recorded in the database includes demographic characteristics (sex and age), medical information (name of the hospital, level of the hospital, dates of visits), disease diagnosis in Chinese and the corresponding International Classification of Diseases, 10th Revision (ICD-10) codes, dates of diagnoses, and cost information. Details of this database have been presented in previous studies [13, 14]. The BMCDE only collects reimbursement data and deletes all personal identifiers, so this study was considered to be exempt from ethical approval because we only used encrypted retrospective information. Study design and participants 
This was a retrospective serial cross-sectional study. All beneficiaries aged $\geq 18$ years-old in the BMCDE from 1 January 2008 to 31 December 2017 were included in the study. Beneficiaries with lack of personal information or unclear diagnosis of disease were excluded. Information from the same individual could be linked anonymously using an encrypted number.

\section{Definition of outcomes}

According to the principal diagnosis, patients with osteoarthritis were extracted by using ICD-10 codes (M13.991, M19.991, M23.491, M24.091, M24.691, M25.591, M25.991, M25.891, M25.491, M24.891, M17.961, M24.661, M25.561, M25.661, M19.821, M24.621, M19.841, M24.651, M25.551, M24.671, and M25.511). The index date was set to the date when osteoarthritis was first diagnosed. Patients newly diagnosed with osteoarthritis were defined as those who first met the criteria for osteoarthritis (no record of osteoarthritis in 2006 and 2007).

\section{Statistical analysis}

Prevalence was calculated by dividing the number of people with osteoarthritis each year by the average number of beneficiaries that year (beneficiaries are calculated by taking the average number of beneficiaries on January 1 and December 31 of each year). Incidence was calculated by dividing the number of people newly diagnosed with osteoarthritis per year by the total person-years of all beneficiaries that year (those who already have osteoarthritis have been subtracted from the beneficiaries). The annual prevalence and incidence rates were standardized through age adjustment, using population data for Beijing from the sixth national census.

We used joinpoint regression to analyze trends in prevalence and incidence rates [15]. Joinpoint regression is a common method to investigate epidemiological time trends that has been used in many studies [16]. This model aims to establish piecewise regression according to the time characteristics of disease distribution, dividing time into different intervals (or phases) through several connection points, and conducting trend fitting and optimization for each interval, so as to evaluate the disease change characteristics of different intervals within the whole time range in more detail. The term joinpoint in the model refers to a significant change in the direction or size of the linear trend found by permutation tests [16]. A log-linear regression model was used in each phase: $\log (y)=\beta_{0}+\beta_{1} x$, where $y$ refers to the prevalence or incidence at year $x$. Annual percent Change (APC), Average Annual percent Change (AAPC), and $95 \% \mathrm{Cls}$ are the main results of joinpoint models, representing the percentage change in prevalence or incidence in a given year compared to the previous year within each interval and over the whole study period, respectively. APC was calculated based on the slope in each phase, using the following formula:

$\operatorname{APC}=\left(\frac{y_{x+1}-y_{x}}{y_{x}}\right) \times 100=\left(e^{\beta_{1}}-1\right) \times 100$

The parameter calculation method of AAPC was used to calculate the regression coefficient of each phase by weighting the span width $w$ of the segmented interval [17], using the formula: $A A P C=\left(e^{\frac{\Sigma w_{i} \beta_{i}}{\Sigma w_{i}}}-1\right) \times 100$. We analyzed differences using $t$-tests for numerical variables and chi-square tests for categorical variables. The $Z$-test was used to analyze the statistical significance of APC and AAPC, with non-significant changes indicating stable trends [17]. A two-tailed $P<0.05$ was considered statistically significant. All statistical analyses were performed using SAS 9.3 (SAS Institute Inc., Cary, $\mathrm{NC}$ ) and the Joinpoint Regression Program (Version 4.8.0.1) from the Surveillance Research Program of the US National Cancer Institute.

\section{Results}

\section{Patient characteristics}

Of the 17.7 million participants, 2,793,467 (16\%) people with osteoarthritis were identified between 2008 and 2017. Most patients were women (60\%), 55-64 years-old (27\%), retired (58\%), diagnosed in tertiary hospitals (53\%), and lived in the city $(75 \%)$. The characteristics of patients with osteoarthritis are shown in Table 1. 
Table 1

Basic characteristics of people with osteoarthritis in Beijing, China, 2008-2017.

\begin{tabular}{|c|c|c|c|c|}
\hline Characteristics & Overall $(n=2,793,467)$ & $\begin{array}{l}\text { Men } \\
(n=1,121,610)\end{array}$ & $\begin{array}{l}\text { Women } \\
(n=1,671,857)\end{array}$ & $P$-value \\
\hline \multicolumn{5}{|c|}{ Level of hospital, \% } \\
\hline Primary & 21 & 22 & 20 & $<0.001$ \\
\hline Secondary & 26 & 27 & 26 & \\
\hline Tertiary & 53 & 51 & 54 & \\
\hline \multicolumn{5}{|l|}{ Age group ${ }^{\star} \%$} \\
\hline $18-34$ yrs & 10 & 9 & 11 & $<0.001$ \\
\hline $35-44$ yrs & 12 & 11 & 13 & \\
\hline $45-54$ yrs & 21 & 17 & 24 & \\
\hline $55-64$ yrs & 27 & 27 & 27 & \\
\hline $65-74$ yrs & 17 & 20 & 15 & \\
\hline $65-84$ yrs & 11 & 13 & 9 & \\
\hline$\geq 85 \mathrm{yrs}$ & 2 & 3 & 1 & \\
\hline \multicolumn{5}{|l|}{ Area, \% } \\
\hline Urban & 75 & 73 & 77 & $<0.001$ \\
\hline Rural & 25 & 27 & 23 & \\
\hline \multicolumn{5}{|l|}{ Working state } \\
\hline On work & 42 & 48 & 39 & $<0.001$ \\
\hline Retired & 58 & 52 & 61 & \\
\hline
\end{tabular}

\section{Prevalence and incidence of osteoarthritis}

Table 2 shows the annual age-standardized prevalence and incidence of diagnosed osteoarthritis in Beijing from 2008 to 2017. 
Table 2

Age-standardised prevalence and incidence of diagnosed osteoarthritis in Beijing, China, 2008-2017.

\begin{tabular}{|c|c|c|c|c|c|c|c|c|c|}
\hline & 2008 & 2009 & 2010 & 2011 & 2012 & 2013 & 2014 & 2015 & 2016 \\
\hline \multicolumn{10}{|c|}{$\begin{array}{l}\text { Prevalence } \\
(\%, 95 \% \\
\text { Cl) }\end{array}$} \\
\hline \multirow[t]{2}{*}{ Overall } & 1.775 & 2.406 & 3.864 & 5.095 & 5.724 & 5.671 & 6.840 & 7.339 & 6.631 \\
\hline & $(1.774,1.776)$ & $(2.405,2.407)$ & $(3.863,3.865)$ & $(5.094,5.097)$ & $(5.722,5.725)$ & $(5.669,5.672)$ & $(6.838,6.841)$ & $(7.337,7.340)$ & $(6.63)$ \\
\hline \multirow[t]{2}{*}{ Men } & 2.114 & 2.819 & 2.378 & 3.202 & 3.320 & 3.355 & 4.248 & 4.650 & 4.232 \\
\hline & $(2.113,2.115)$ & $(2.817,2.820)$ & $(2.376,2.379)$ & $(3.201,3.204)$ & $(3.318,3.322)$ & $(3.354,3.357)$ & $(4.246,4.249)$ & $(4.648,4.652)$ & $(4.23$ \\
\hline \multirow[t]{2}{*}{ Women } & 1.429 & 1.984 & 5.382 & 7.028 & 8.179 & 8.035 & 9.487 & 10.085 & 9.081 \\
\hline & $(1.427,1.430)$ & $(1.983,1.985)$ & $(5.380,5.384)$ & $(7.026,7.030)$ & $(8.176,8.181)$ & $(8.033,8.038)$ & $(9.484,9.489)$ & $(10.082,10.087)$ & $(9.07$ \\
\hline \multicolumn{10}{|c|}{$\begin{array}{l}\text { Incidence } \\
\text { (per 1000 } \\
\text { person- } \\
\text { years, 95\% } \\
\mathrm{Cl} \text { ) }\end{array}$} \\
\hline \multirow[t]{2}{*}{ Overall } & 17.23 & 23.48 & 25.42 & 34.48 & 35.35 & 30.49 & 38.34 & 31.65 & $25.5 \mathrm{c}$ \\
\hline & $(17.22,17.24)$ & $(23.47,23.49)$ & $(25.41,25.43)$ & $(34.47,34.49)$ & $(35.34,35.37)$ & $(30.48,30.51)$ & $(38.33,38.35)$ & $(31.64,31.66)$ & $\left(25.5^{\prime}\right.$ \\
\hline \multirow[t]{2}{*}{ Men } & 9.17 & 13.21 & 14.89 & 20.55 & 21.47 & 19.53 & 26.10 & 22.32 & $18.2 \varepsilon$ \\
\hline & $(9.16,9.18)$ & $(13.20,13.22)$ & $(14.88,14.90)$ & $(20.54,20.56)$ & $(21.46,21.49)$ & $(19.52,19.54)$ & $(26.09,26.12)$ & $(22.30,22.33)$ & $(18.2$ \\
\hline \multirow[t]{2}{*}{ Women } & 25.46 & 33.96 & 36.16 & 48.70 & 49.53 & 41.69 & 50.84 & 41.18 & 33.06 \\
\hline & $(25.45,25.47)$ & $(33.95,33.98)$ & $(36.15,36.18)$ & $(48.68,48.72)$ & $(49.51,49.55)$ & $(41.67,41.71)$ & $(50.82,50.86)$ & $(41.17,41.20)$ & (33.0 \\
\hline
\end{tabular}

Note: Population data for Beijing from China's 6th national census were used to standardise prevalence and incidence.

(Please place the table under the paragraph about "Prevalence and incidence of osteoarthritis")

The 10-year average age-standardized prevalence of osteoarthritis in Beijing was $5.2 \%$ from 2008 to 2017. The lowest point appeared in 2008, which was $1.8 \%$, and the highest point appeared in 2015 , which was $7.3 \%$. The annual age-standardized prevalence of women was higher than that of men between 2010 and 2017. The prevalence of osteoarthritis gradually increased with age, and the rate of increase became greater after 55 years-old (Fig. 1). The average crude prevalence of the decade was $14.9 \%$ for people over 55 years-old; $10.7 \%$ for males and $20.4 \%$ for females.

The 10-year average age-standardized incidence of osteoarthritis was 28.5 per 1000 person-years. The lowest point was 17.2 per 1000 person-years in 2008 , and the highest point was 38.3 per 1000 person-years in 2015. The 10-year average crude incidence rate for people over 55 years-old was 50.1 per 1000 person-years; 41.1 per 1000 person-years for males and 62.0 per 1000 person-years for females.

\section{Trends in the prevalence and incidence of osteoarthritis}

Table 3 shows the trends in the age-standardized prevalence and incidence of diagnosed osteoarthritis in Beijing from 2008 to 2017. The prevalence increased significantly with an AAPC of $16.4 \%(P<0.05)$ during this decade. There were two different trends in prevalence during this period and one joinpoint in 2011 . The period from 2008 to 2011 was a phase of rapid increase, with an APC of 44.3\% $(P<0.05)$. This increasing trend in prevalence was observed among all age groups, but the AAPC was greater in people under 35 years-old $(36.1 \%, P<0.05)$. The annual crude prevalence of osteoarthritis in people under 35 yearsold from 2008 to 2017 is shown in Fig. 2. 
Table 3

Changes in the age-standardised prevalence and incidence of diagnosed osteoarthritis in Beijing, China, 2008-2017 (\%).

\begin{tabular}{|c|c|c|c|c|c|c|}
\hline & & \multicolumn{2}{|l|}{ Trend 1} & \multicolumn{2}{|c|}{ Trend 2} & \multirow{2}{*}{$\begin{array}{l}\text { Average annual percentage change } \\
(95 \% \mathrm{Cl})\end{array}$} \\
\hline & & Period & $\begin{array}{l}\text { Annual percentage change } \\
(95 \% \mathrm{Cl})\end{array}$ & Period & $\begin{array}{l}\text { Annual percentage change } \\
(95 \% \mathrm{Cl})\end{array}$ & \\
\hline \multirow[t]{8}{*}{ Prevalence } & Overall & $\begin{array}{l}2008- \\
2011\end{array}$ & $44.3(8.7,91.7)^{\star}$ & $\begin{array}{l}2011- \\
2017\end{array}$ & $4.5(-0.4,9.8)$ & $16.4(7.8,25.6)^{\star}$ \\
\hline & \multicolumn{6}{|l|}{ Gender } \\
\hline & Men & - & - & - & - & $7.8(4.7,10.9)^{\star}$ \\
\hline & Women & $\begin{array}{l}2008- \\
2011\end{array}$ & $76.2(20.4,157.9)^{\star}$ & $\begin{array}{l}2011- \\
2017\end{array}$ & $3.4(-1.9,9)$ & $23.5(11.7,36.5)^{\star}$ \\
\hline & \multicolumn{6}{|c|}{ Age group, years } \\
\hline & $18-34$ & $\begin{array}{l}2008- \\
2011\end{array}$ & $110.8(54.4,187.9)^{\star}$ & $\begin{array}{l}2011- \\
2017\end{array}$ & $9.4(6.1,12.7)^{\star}$ & $36.1(25.6,47.5)^{*}$ \\
\hline & $35-44$ & $\begin{array}{l}2008- \\
2012\end{array}$ & $65.9(32.7,116.4)^{\star}$ & $\begin{array}{l}2012- \\
2017\end{array}$ & $4.1(-1.9,10.4)$ & $29.2(18.5,40.9)^{\star}$ \\
\hline & $\geq 45$ & $\begin{array}{l}2008- \\
2011\end{array}$ & $45.7(11.4,90.6)^{\star}$ & $\begin{array}{l}2011- \\
2017\end{array}$ & $3.7(-1.2,8.9)$ & $16.2(8.0,24.9)^{\star}$ \\
\hline \multirow[t]{8}{*}{ Incidence } & Overall & - & - & - & - & $1.2(-5.1,7.9)$ \\
\hline & \multicolumn{6}{|l|}{ Gender } \\
\hline & Men & - & - & - & - & $4.2(-2.6,11.3)$ \\
\hline & Women & - & - & - & - & $0.1(-6.3,6.9)$ \\
\hline & \multicolumn{6}{|c|}{ Age group, years } \\
\hline & $18-34$ & $\begin{array}{l}2008- \\
2012\end{array}$ & $53.8(26.6,88.5) \star$ & $\begin{array}{l}2012- \\
2017\end{array}$ & $2.4(-3.2,8.3)$ & $22.7(14.1,32)^{\star}$ \\
\hline & $35-44$ & $\begin{array}{l}2008- \\
2012\end{array}$ & $54.9(17.5,104.1)^{\star}$ & $\begin{array}{l}2012- \\
2017\end{array}$ & $-4.0(-12.0,4.7)$ & $18.7(7.4,31.3)^{\star}$ \\
\hline & $\geq 45$ & $\begin{array}{l}2008- \\
2012\end{array}$ & $16.3(-1.6,37.3)$ & $\begin{array}{l}2012- \\
2017\end{array}$ & $-10.3(-19.6,0)$ & $0.6(-6.4,8.3)$ \\
\hline \multicolumn{7}{|c|}{ Note: $95 \% \mathrm{Cl}, 95 \%$ confidence interval. ${ }^{\star} P<0.05$ was considered statistically significant. } \\
\hline (Please pla & the table & ider the & graph about "Trends in the & ce and $\mathrm{i}$ & nce of osteoarthritis") & \\
\hline
\end{tabular}

The age-standardized incidence of osteoarthritis remained stable from 2008 to 2017, with a non-significant AAPC of $1.2 \%(P>0.05)$, and no significant joinpoint. Joinpoint regression showed that the AAPC in the incidence of patients aged 18-34 years-old was greater than that of patients aged 35-44 yearsold (22.7\% vs. 18.7\%). Moreover, there was a joinpoint in 2012 for both these age groups. The period from 2008 to 2012 was a phase of rapid increase, with an APC of $53.8 \%(P<0.05)$ in the $18-34$ age group and $54.9 \%(P<0.05)$ in the $35-44$ age group.

\section{Discussion}

The present study is the first study to our knowledge to describe trends in the prevalence and incidence of osteoarthritis in China. Using data from the healthinsurance claims of nearly 18 million people, we found that the 10-year average age-standardized prevalence and incidence rates of osteoarthritis in Beijing were, respectively, $5.21 \%$ and 28.54 per 1000 person-years. Furthermore, prevalence increased significantly within a decade. In addition, we also found that the AAPC in the prevalence and incidence during the decade was the largest in the low-age group (18-34 years), indicating that osteoarthritis was diagnosed at younger ages.

Our results showed that the age-standardized prevalence of osteoarthritis in people over 18 years-old was $5.21 \%$, which is close to the findings of the Australian scholar Minaur (5.5\%) [18]. The highest prevalence of osteoarthritis was 20.7\% [19] and the lowest was 1.6\% [20] in relevant and comparable studies. Compared with related studies in other countries, the prevalence of osteoarthritis in Beijing is at a low-medium level. We attribute the difference in prevalence among studies to differences in race, life and work styles, and other variables. Furthermore, the prevalence observed in the present study increased significantly within a decade, which is similar to the change in prevalence observed in other countries, such as the United States and the United Kingdom [6, 21]. The reason for this may be the aging of the population and increased risk factors for osteoarthritis (such as low physical activity and high body mass index) in recent years [22-24]. In addition, the present study found the AAPC in the prevalence of osteoarthritis was greatest in the age group under 35 yearsold. We should be alert to the phenomenon that the rate of osteoarthritis is increasing among young people, not only among older adults. More efforts are needed in the future to prevent osteoarthritis in young people.

Previous studies have shown that the prevalence and incidence of osteoarthritis are higher in women than in men [25-27], which is consistent with the results of the present study. This phenomenon may be attributed to differences in hormone levels, muscle strength, and health-seeking behavior between the genders 
[28-30]. Estrogen levels in postmenopausal women are significantly lower than premenopausal and male levels, which may affect cartilage metabolism and change the mechanical environment of joints [31]. Moreover, men and women have different sensitivity and tolerance to disease, and women are more likely to seek timely medical treatment than men are [32]. This suggests that men may be less likely to be diagnosed with osteoarthritis, which is reflected in the lower prevalence and incidence among men in this study.

It is known that the prevalence and incidence of osteoarthritis increases with age. Our study showed that the prevalence and incidence of osteoarthritis increased significantly after 55 years-old, and that the average crude prevalence from 2008 to 2017 of people over 55 years-old was $14.86 \%$ : $10.65 \%$ in males and $20.36 \%$ in females. These results are consistent with the results of other studies [33-35]. The reasons may include the following [30, 36, 37]: (i) the cell functions and properties of articular cartilage change with age and it responds differently to cytokines and growth factors; (ii) the articular cartilage secretes less synovial fluid with age, which reduces lubrication of the joints; (iii) muscle strength is reduced with age, so it is difficult to support the surrounding articular cartilage, thereby accelerating cartilage wear; and (iv) after menopause, changes in hormone levels can cause bone hyperplasia and accelerate the onset and progression of osteoarthritis. However, in our study, the prevalence and incidence of osteoarthritis in people over 85 years-old were lower than they were in the 55-64 and 65-74 age groups. The explanation for this may be related to an increased comorbidity rate and a decreased rate in medical visits due to osteoarthritis in this group of people. Another possible explanation for this phenomenon is survivor bias, which allows relatively healthy people to survive to the oldest age group.

This study has certain strengths. Currently, there is a lack of epidemiological studies on large samples of people with osteoarthritis in China. We used data from the health-insurance claims of nearly 18 million people to estimate the prevalence and incidence of osteoarthritis in Beijing in the past 10 years, and determined the prevalence trend for osteoarthritis. These findings about osteoarthritis could provide valuable evidence for other developing cities in China, and even in cities in other countries in the future. Moreover, the estimates of prevalence and incidence were based on a dynamic population, which is closer to realworld population changes.

The limitations of this study include the following. Since the data were based on hospital visits, we could not obtain information about people who suffered from osteoarthritis but did not see a doctor. This may result in an underestimation of prevalence and incidence rates. In addition, although the BMCDE covers more than $80 \%$ of the resident population of Beijing, we could not obtain information about some immigrants in this city, which may cause selection bias. Finally, because the BMCDE includes only claims data, information on socioeconomic status and health behaviors was not available. Therefore, we could not do a more detailed analysis, such as the identification of risk factors.

\section{Conclusion}

Using data from the BMCDE, we observed that the average age-standardized prevalence of diagnosed osteoarthritis in Beijing over a decade was at a low-tomedium level relative to world levels. Furthermore, our analyses showed that the annual prevalence rate increased significantly from 2008 to 2017 , and that osteoarthritis was being diagnosed at younger ages. Therefore, we should pay attention to the younger trend of osteoarthritis.

\section{Declarations}

\section{Conflicts of Interest}

The authors declare that they have no conflict of interest.

\section{Acknowledgements}

We would like to thank the native English-speaking scientists of Elixigen Company (Huntington Beach, California) for editing our manuscript; and Dr. Yongchen Ma for editing our figure.

\section{Role of the funding source}

This work was supported by National Natural Science Foundation of China (No. 81703291, 81872695, 81972158).

\section{Author contributions}

YH Hu and SM Shang contributed to the study concept. YH Hu and SM Shang had full access to all the data in this study and take responsibility for the integrity of the data. HB Chen and JH Wu performed the data analysis, and drafted the manuscript. ZJ Wang, Y Wu and T Wu contributed to the statistical analysis and table's development of this article.YQ Wu, MY Wang, SY Wang, XW Wang, JT Wang, H Yu revised the draft critically for important intellectual content. All the authors read and approved the final manuscript.

\section{Ethics statement}

This study was considered exempted from Institutional Review Board approval because this study were for administrative purposes and do not have any identifying personal information such as full name and citizen's ID number.

\section{Consent for publication}

Not applicable. 


\section{References}

1. McAlindon, T.E., et al., OARSI guidelines for the non-surgical management of knee osteoarthritis. Osteoarthr Cartilage, 2014. 22(3): p. 363-88.

2. Glyn-Jones, S., et al., Osteoarthritis. Lancet, 2015. 386(9991): p. 376-87.

3. Chronic rheumatic conditions. . [cited 201513 December]; Available from: http://www.who.int/chp/topics/rheumatic/en/.

4. XY Zeng, et al., Burden of disease in China and provincial administrative regions, 1990-2016. Chinese Circulation Journal, 2018. 246(12): p. 7-18.

5. Kiadaliri, A.A., et al., High and rising burden of hip and knee osteoarthritis in the Nordic region, 1990-2015. Acta Orthop, 2018. 89(2): p. 177-83.

6. Nguyen, et al., Increasing prevalence of knee pain and symptomatic knee osteoarthritis: survey and cohort data. Ann Intern Med, 2011. 155(11): p. 725-23.

7. Deshpande, B.R., et al., Number of Persons With Symptomatic Knee Osteoarthritis in the US: Impact of Race and Ethnicity, Age, Sex, and Obesity. Arthritis Care Res (Hoboken), 2016. 68(12): p. 1743-50.

8. Jordan, J.M., et al., Prevalence of hip symptoms and radiographic and symptomatic hip osteoarthritis in African Americans and Caucasians: the Johnston County Osteoarthritis Project. J Rheumatol, 2009. 36(4): p. 809-15.

9. CH Zang, et al., Epidemiological study on knee osteoarthritis in Taiyuan City. Chinese Journal of Internal Medicine, 2006. 45(7): p. 533-6.

10. Jiang, L., et al., Prevalence and associated factors of knee osteoarthritis in a community-based population in Heilongjiang, Northeast China. Rheumatol Int, 2012. 32(5): p. 1189-95.

11. Bahri Khomami, M., et al., The role of maternal obesity in infant outcomes in polycystic ovary syndrome-A systematic review, meta-analysis, and metaregression. Obes Rev, 2019. 20(6): p. 842-58.

12. Loader, J., et al., The continuums of impairment in vascular reactivity across the spectrum of cardiometabolic health: A systematic review and network meta-analysis. Obes Rev, 2019. 20(6): p. 906-20.

13. Wu, Y., et al., Prescription of antibacterial agents for acute upper respiratory tract infections in Beijing, 2010-2012. Eur J Clin Pharmacol, 2016. 72(3): p. $359-64$.

14. Wu, J., et al., Association between ambient fine particulate matter and adult hospital admissions for pneumonia in Beijing, China. Atmos Environ, 2020. 231: p. 117497.

15. Zghebi, S.S., et al., Examining trends in type 2 diabetes incidence, prevalence and mortality in the UK between 2004 and 2014. Diabetes Obes Metab, 2017. 19(11): p. 1537-45.

16. Kim, H.J., et al., Permutation tests for joinpoint regression with applications to cancer rates. Stat Med, 2000. 19(3): p. 335-51.

17. Clegg, L.X., et al., Estimating average annual per cent change in trend analysis. Stat Med, 2009. 28(29): p. 3670-82.

18. Minaur, N., et al., Rheumatic disease in an Australian Aboriginal community in North Queensland, Australia. A WHO-ILAR COPCORD survey. J Rheumatol, 2004. 31(5): p. 965-72.

19. Davatchi, F., et al., Epidemiology of rheumatic diseases in Iran from analysis of four COPCORD studies. Int J Rheum Dis, 2016. 19(11): p. 1056-62.

20. Obregon-Ponce, A., et al., Prevalence of musculoskeletal diseases in Guatemala, Central America: the COPCORD study of 2 populations. J Clin Rheumatol, 2012. 18(4): p. 170-4.

21. Leyland, K.M., et al., The natural history of radiographic knee osteoarthritis: a fourteen-year population-based cohort study. Arthritis Rheum, 2012. 64(7): p. 2243-51.

22. Kulkarni, K., et al., Obesity and osteoarthritis. Maturitas, 2016. 89: p. 22-8.

23. W.F.S.N. Physical Activity. 2015; Available from: http://www.who.int/mediacentre/factsheets/fs385/en/.

24. Dekker, J., G.M. van Dijk, and C. Veenhof, Risk factors for functional decline in osteoarthritis of the hip or knee. Curr Opin Rheumatol, 2009. 21(5): p. 520-4. 25. Pal, C.P., et al., Epidemiology of knee osteoarthritis in India and related factors. Indian J Orthop, 2016. 50(5): p. 518-22.

26. Kodama, R., et al., Prevalence of hand osteoarthritis and its relationship to hand pain and grip strength in Japan: The third survey of the ROAD study. Mod Rheumatol, 2016. 26(5): p. 767-73.

27. Tang, X., et al., The prevalence of symptomatic knee osteoarthritis in China: results from the China Health and Retirement Longitudinal Study. Arthritis \& Rheumatology, 2016. 68(3): p. 648-53.

28. Prieto-Alhambra, D., et al., Incidence and risk factors for clinically diagnosed knee, hip and hand osteoarthritis: influences of age, gender and osteoarthritis affecting other joints. Ann Rheum Dis, 2014. 73(9): p. 1659-64.

29. Sun, X., et al., Osteoarthritis in the middle-aged and elderly in China: prevalence and influencing factors. Int J Environ Res Public Health, 2019. 16(23).

30. Felson, D.T., et al., Risk factors for incident radiographic knee osteoarthritis in the elderly: the Framingham Study. Arthritis Rheum, 1997. 40(4): p. 728-33.

31. Su, Y., et al., Epidemiological study on symptomatic knee osteoarthritis in middle-aged and elderly people in Guangzhou area. Chin. J. Jt. Surg., 2010. 4: p. 2-6.

32. Zhou, Z. and Z. Zou, Investigation on some factors affecting patient's medical treatment behavior. . Chinese Hospital Management, 1994 : p. $28-31$.

33. Losina, E., et al., Lifetime risk and age at diagnosis of symptomatic knee osteoarthritis in the US. Arthritis Care Res, 2013. 65(5): p. 703-11.

34. Park, J.H., et al., Prevalence of symptomatic hip, knee, and spine osteoarthritis nationwide health survey analysis of an elderly Korean population. Medicine (Baltimore), 2017. 96(12): p. e6372.

35. Cross, M., et al., The global burden of hip and knee osteoarthritis: estimates from the global burden of disease 2010 study. Ann Rheum Dis, 2014. 73(7): p. 1323-30. 
36. Blagojevic, M., et al., Risk factors for onset of osteoarthritis of the knee in older adults: a systematic review and meta-analysis. Osteoarthr Cartilage, 2010. 18(1): p. 24-33.

37. Mikesky, A.E., et al., Effects of strength training on the incidence and progression of knee osteoarthritis. Arthritis Rheum, 2006. 55(5): p. 690-9.

\section{Figures}

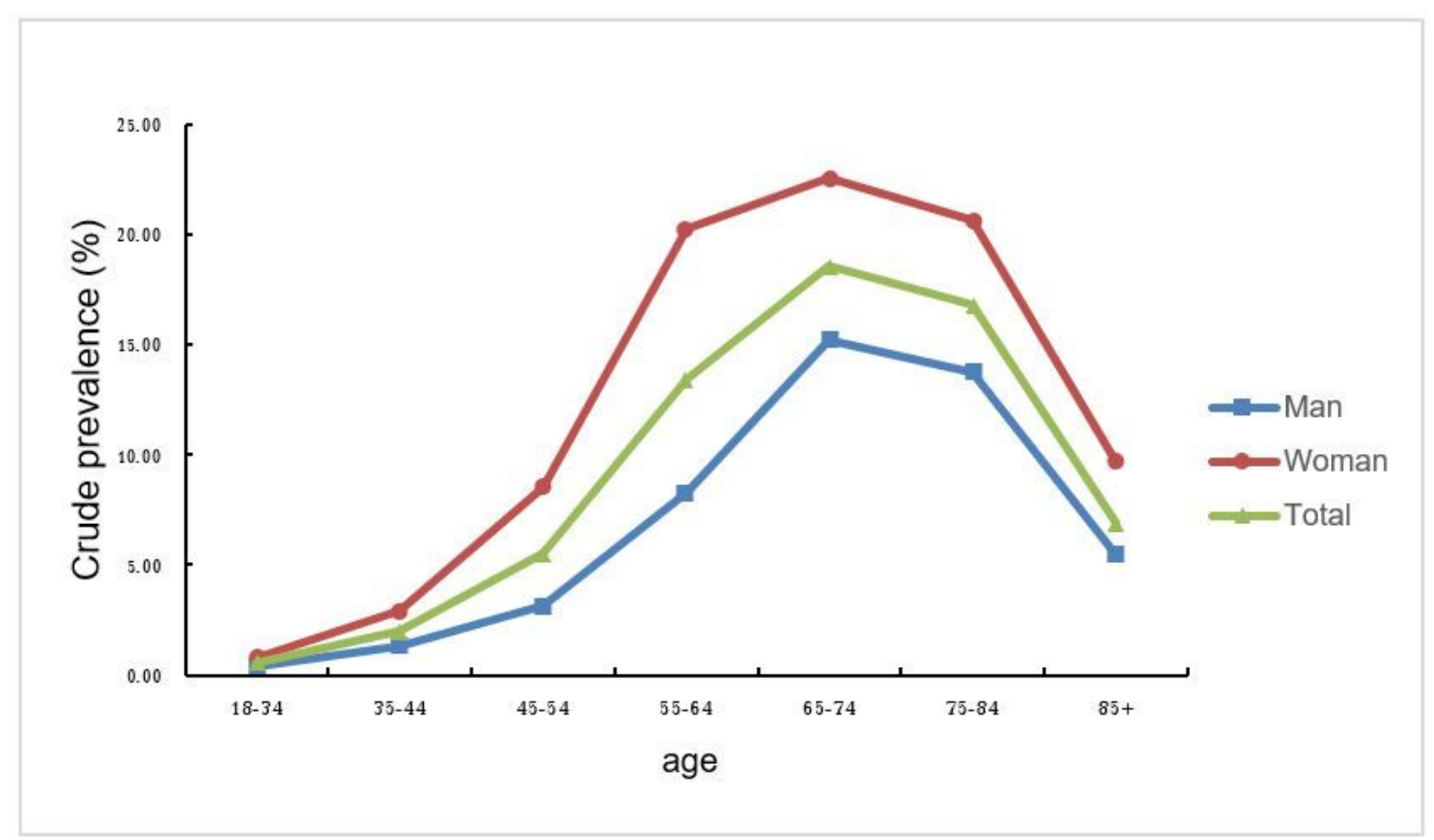

Figure 1

Average crude prevalence of osteoarthritis for all age groups in Beijing, China, 2008-2017 (\%).

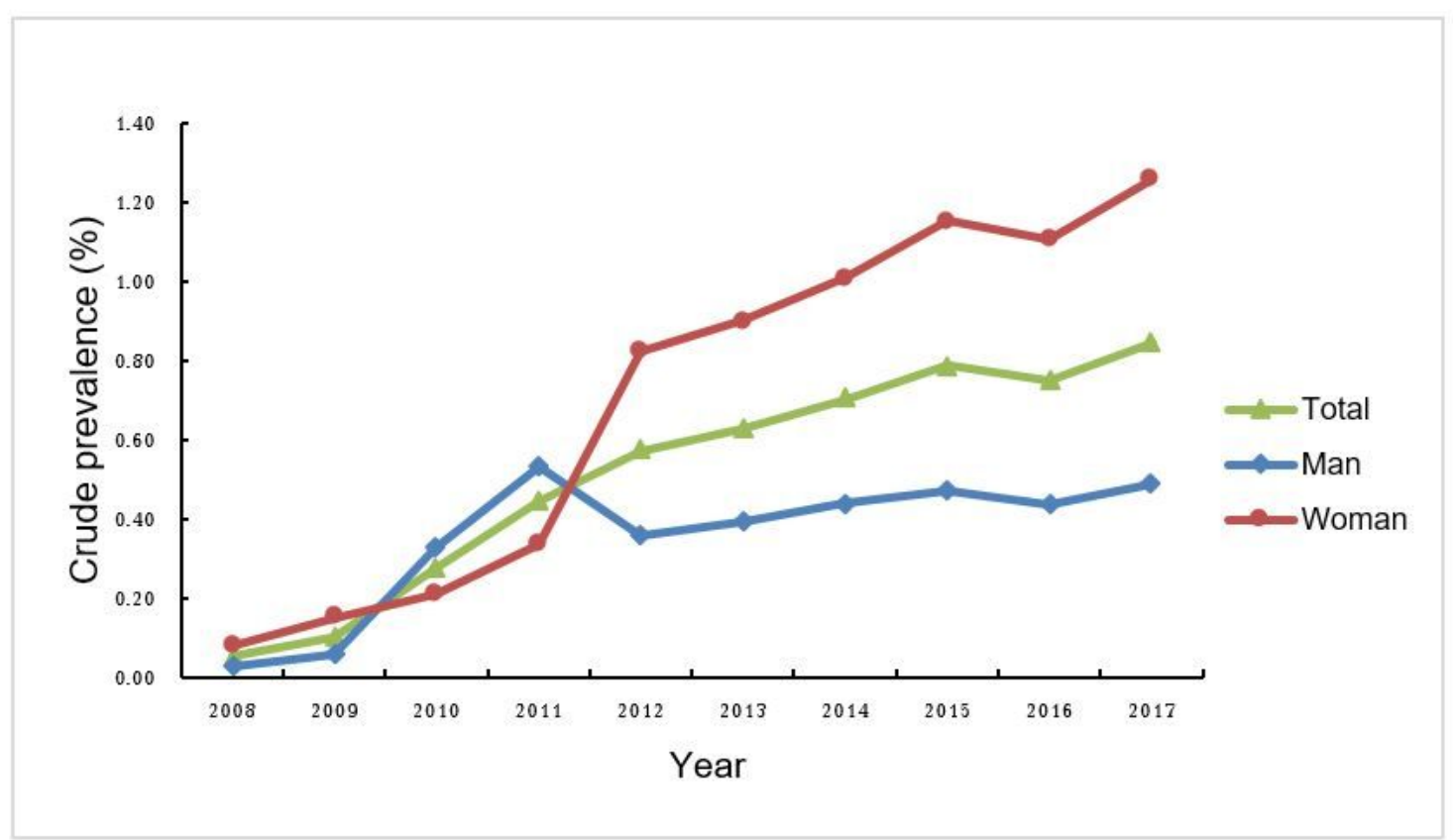

Figure 2

Annual crude prevalence of osteoarthritis in people under 35 years old in Beijing from 2008 to 2017 (\%). 